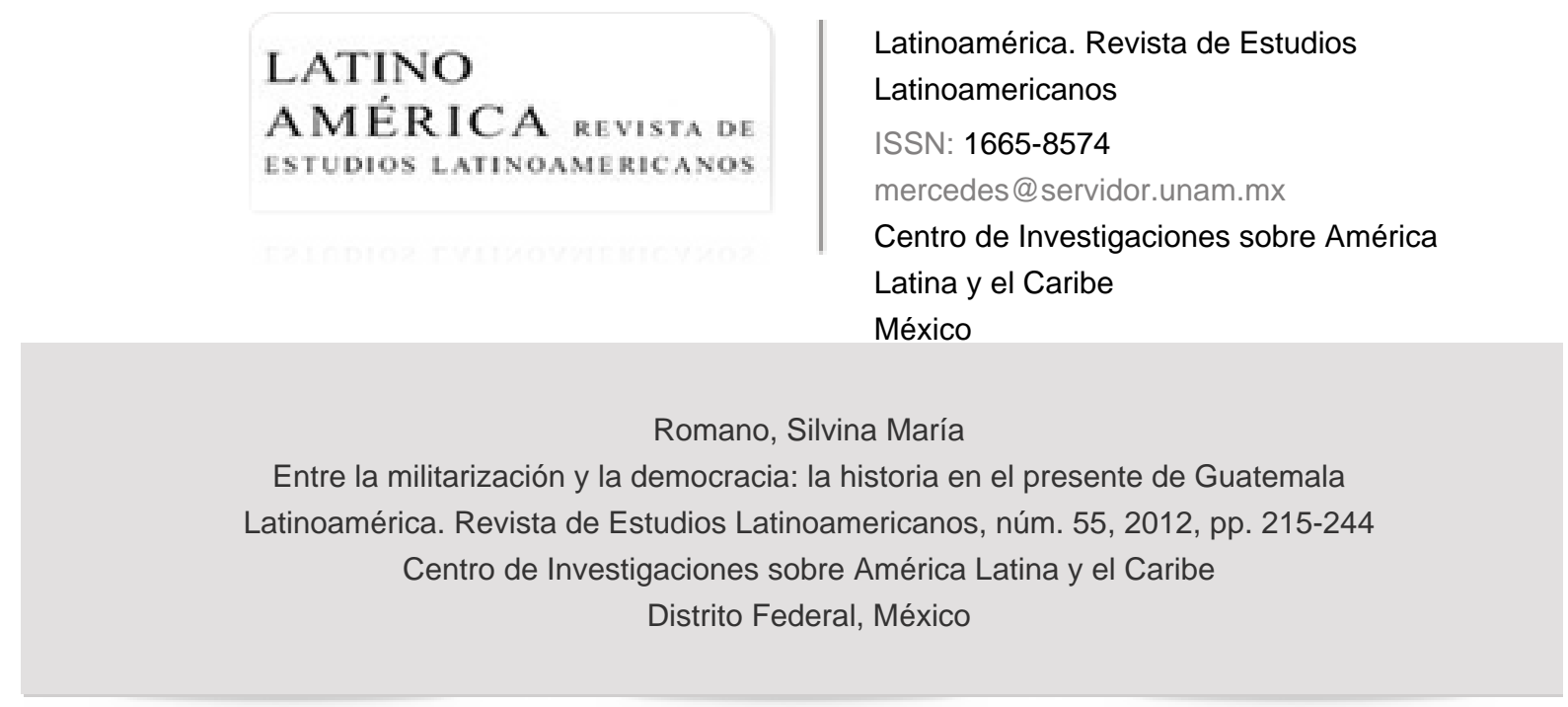

Disponible en: http://www.redalyc.org/articulo.oa?id=64024698009

- Cómo citar el artículo

- Número completo

- Más información del artículo

- Página de la revista en redalyc.org

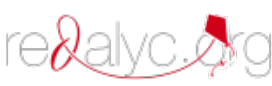

Sistema de Información Científica

Red de Revistas Científicas de América Latina, el Caribe, España y Portugal Proyecto académico sin fines de lucro, desarrollado bajo la iniciativa de acceso abierto 


\title{
Entre la militarización \\ y la democracia: la historia en el presente de Guatemala
}

\author{
Silvina María Romano*
}

Resumen: Con el derrocamiento de Arbenz (1954) se fue consolidando el proceso de militarización de la política como alternativa frente a sectores en permanente reivindicación de sus derechos y como respuesta a un movimiento contrarrevolucionario heterogéneo y carente de legitimidad. Esto contribuyó a profundizar un orden económico y políitco excluyente (asentado en el modelo primario-exportador), atravesado por la violencia diaria perpetrada desde el Estado. La cúpula de las Fuerzas Armadas, como parte de la clase dominante, adquirió un papel protagónico en la transición de gobiernos militarizados a gobiernos democráticos. La inconsistencia del poder civil frente al militar debilitó la democracia y los logros de los Acuerdos de Paz. La asunción de Otto Pérez Molina como presidente (ex militar vinculado a los crímenes perpetrados en los ochenta) invita a reflexionar sobre las continuidades y los cambios en la relación entre las Fuerzas Armadas y el poder civil, la estructura económica y los límites de la democracia.

Palabras Clave: Guatemala, Militarización, Democracia, Desigualdad.

ABSTRAC: With the overthrowing of Arbenz (1954), the militarization process grew stronger as an alternative to neutralize various sectors that claimed their own rights, as well as an echo to the heterogeneous and disorganized counterrevolutionary movement. This process contributed to enlarge a system based on political and economic exclusion (organized around commodity exports), which was also affected by daily violence perpetrated by the state. The highest of the armed forces, as a part of the dominant class, acquired a main role in the transition from military regimes to democratic governments. The weakness of the civil power towards the military contributed to the erosion of democracy and the achievements of peace agreements. The new president, Otto Perez Molina (ex military involved in the crimes perpetrated during the 80's) invites us to think about the continuities and changes in the relationship between the armed forces and civil power; the economic structure and the limits of democracy.

Key words: Guatemala, Militarization, Democracy, Inequality.

*Becaria de la Coordinación de Humanidades-unam (silvinamceleste@gmail.com). 


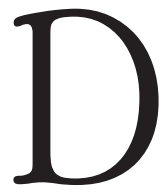

urante la Revolución guatemalteca, las presidencias de Arévalo (1945-1951) y Arbenz (1951-1954) intentaron combinar los principios formales de la democracia procedimental con cambios en la estructura socioeconómica y política (democracia sustantiva), ${ }^{1}$ a fin de lograr una distribución más equitativa de la riqueza y los recursos. Este proyecto fue desarticulado a partir del derrocamiento de Arbenz en junio de 1954.

La presencia de las Fuerzas Armadas en la esfera política formal o su influencia directa en la toma de decisión (desde mediados de los cincuenta hasta mediados de los ochenta) fue la plataforma sobre la cual se reprodujo una espiral de violencia en zonas rurales y urbanas que pervive hasta nuestros días. El heterogéneo grupo reaccionario no propuso un claro proyecto de país (pero sí procuró eliminar de raíz las reformas establecidas por los gobiernos de Arévalo y Arbenz), agrupó a los sectores conservadores y de relevancia económica local, la clase media anticomunista y las Fuerzas Armadas, sumado a la alianza con la élite del poder estadounidense. A pesar de su heterogeneidad, se mantuvo en el poder gracias a la utilización de programas de contrainsurgencia implementados desde el mismo Estado contra el "enemigo interno", que incluía a cualquier sector que promoviera reformas capaces de modificar la estructura económica, política y social. Esto se articuló con un retorno y profundización de la liberalización de la economía, que se combinó hacia mediados de los ochenta con una transición a la democracia donde no logró prevalecer con claridad el poder civil, contexto en el que se firmaron los acuerdos de paz.

Hoy por hoy, Guatemala es uno de los países más pobres de América Latina, con elevados índices de mortalidad infantil, de desnutrición y de concentración de la tierra y la riqueza. Como corolario de esta enorme desigualdad, presenta

1 Para revisar la relación-tensión entre los aspectos formales (procedimentales) de la democracia y los aspectos sustantivos (redistribución, justicia, etc.) en el sistema capitalista véanse Edelberto Torres Rivas, La piel de Centroamérica, Guatemala, FLACSO/ASDI, 2007; Ellen Meiksins Wood, Democracia contra capitalismo: la renovación del materialismo histórico, México, Siglo xxi, 2000; Atilio Borón, Tras el Búbo de Minerva: mercado contra democracia en el capitalismo de fin de siglo, Buenos Aires, CLACSO/FCE, 2000; Claude Ake, The feasibility of democracy in Africa, Dakar, CODESRIA, 2003. 
uno de los niveles de violencia más altos del continente ¿cómo se relaciona la militarización con la reproducción de una estructura económica desigual que, entre otras cuestiones, obstaculiza los avances hacia una democracia sustantiva más allá de los logros en el plano procedimental? Se propone responder a este interrogante desde una perspectiva histórica que ayude a comprender los procesos actuales. Así, se realiza un breve repaso de la Revolución guatemalteca, en particular de la relación entre las premisas sobre seguridad, organización política, estructura económica primaria-exportadora y las Fuerzas Armadas. Este es el punto de partida para analizar los cambios y continuidades en el papel desempeñado por dicho sector en procesos fundamentales para la historia guatemalteca, como el surgimiento de la guerrilla y su desarticulación en la década de 1960, el resurgimiento de los movimientos de masas y la lucha armada en los setenta y las cruentas tácticas de contrainsurgencia de la década de 1980. En consideración a tales antecedentes, se abordarán algunas características de la democracia procedimental y los Acuerdos de Paz y su relación con el contexto económico. Es fundamental anticipar que a lo largo del texto aparece una y otra vez la presencia directa o indirecta del gobierno y del sector privado estadounidenses, pues son actores protagónicos de los sucesos guatemaltecos.

\section{LA REVOLUCIÓN GUATEMALTECA Y LA LUCHA}

POR UNA ESTRUCTURA ECONÓMICO-POLÍTICA MENOS DESIGUAL

La economía guatemalteca se configuró como agroexportadora desde la época de la Colonia. Con el transcurso de los siglos, se consolidó el sistema latifundiominifundio, caracterizado por la concentración de la tierra y la mano de obra indígena servil. De este modo, se estructuró un patrón de dependencia y subdesarrollo - común a América Latina en tanto espacio colonial-, ${ }^{2}$ en el que Guatemala producía y exportaba materias primas y compraba manufacturas a España y luego a otros países centrales.

2 André Gunder Frank, Capitalismo y subdesarrollo en América Latina, Buenos Aires, Signos, 1970. En http://www.eumed.net/cursecon/textos/Frank/index.htm. 
De acuerdo con las necesidades de las metrópolis, hubo variaciones en las materias primas exportadas, destacándose los añiles y luego el café, que para la época de la Primera Guerra Mundial implicaba 90\% de los ingresos de exportaciones. En dicho periodo aumentó paulatinamente la producción de plátano. ${ }^{3}$ Desde inicios del siglo xx, el gobierno guatemalteco otorgó beneficios y atenciones especiales a la United Fruit Company (UFCo), que devino en "un Estado dentro del Estado guatemalteco", pues a finales de la Segunda Guerra Mundial, controlaba 40 mil puestos de trabajo, sus inversiones se aproximaban a los $60 \mathrm{mi}-$ llones de dólares, era dueña de los telégrafos y teléfonos de Guatemala, administraba el único puerto de importancia, y la International Railways of Central America (IRCA) poseía $1500 \mathrm{~km}$ de líneas férreas de Guatemala, es decir, la mayor parte. ${ }^{4}$

En junio de 1944, en el marco de la denominada primavera democrática en América Latina, ${ }^{5}$ lo que comenzó como una huelga estudiantil terminó como una huelga general en contra del gobierno de Jorge Ubico (1931-1944), que renunció pero designó en su lugar a un triunvirato que puso en el Poder Ejecutivo a Federico Ponce, quien estaba de hecho bajo el mando del ex dictador y, además de postergar el llamado a elecciones, no prometió ningún cambio respecto al régimen anterior. Así es que el 20 de octubre, la movilización iniciada en junio culminó con un levantamiento armado encabezado por una parte del Ejército, estudiantes y obreros. Se conformó un Junta Revolucionaria Interina, liderada por los militares Arbenz y Arana y el civil Toriello, que llamó a elecciones presidenciales. En la contienda electoral, salió victorioso José Arévalo con 85\% de los votos. Este gobierno abrió una etapa de democracia nunca antes vivida en Guatemala, que buscó combinar los aspectos formales con los aspectos sustantivos de la democracia. Cuando asumió la presidencia había 70\% de analfabetos, 2\%

3 Andrea Brown, "Tierra de unos cuantos: la propiedad del campo en Guatemala", en David Tobis y Susane Jonas, Guatemala, una historia inmediata, México, Siglo xxI, 1979, pp. 29-52.

4 Stephen Schlesinger y Stephen Kinzer, Fruta amarga. La CIA en Guatemala, México, Siglo xxI, 1987 , p. 26.

5 Joseph Gilbert M., "What we know now and should know: bringing Latin America more meaning fully into Cold War studies", en Joseph Gilbert y Daniela Spenser [eds.], In from the cold. Latin America's new encounter with the Cold War, Durham, N.C., Duke University Press, 2008. 
de los terratenientes era dueño de las tierras cultivables y $72 \%$ de la mano de obra estaba ocupada en el campo. ${ }^{6}$

Con este gobierno entró en vigencia la nueva Constitución elaborada por la Asamblea Constituyente de 1945, que, entre otras cuestiones, convocaba al sufragio universal, a un sistema multipartidista y promovía la libertad de expresión, de prensa, etc. Se implementaron programas de bienestar social, como programas de viviendas, escuelas y hospitales. Se reorganizó el sistema educativo en el plano nacional y se llevaron a cabo campañas de alfabetización, junto con programas de salud. Por primera vez se concedió a los trabajadores un seguro social. Con la nueva Constitución y el código de trabajo también se abolieron leyes y prácticas coloniales como las leyes de vagancia y el trabajo forzado?

Arévalo impulsó en buena medida la democracia exigida por el movimiento del 44, pero no logró avanzar en cambios vinculados a la estructura productiva: no se enfrentó a los enclaves extranjeros ni abordó el problema de la enorme desigualdad en la tenencia de la tierra. Estos dos aspectos, en cambio, sí fueron parte del programa del gobierno de Jacobo Arbenz (1951-1954), quien llegó al gobierno mediante elecciones democráticas, con un programa de desarrollo que coincidía, de modo general, con los postulados de la Comisión Económica Para América Latina (CEPAL) e, incluso, con las recomendaciones del Banco Internacional de Reconstrucción y Fomento (BIRF). ${ }^{8}$ El problema era que para llevar a cabo un programa de industria sustitutiva de importaciones (ISI) y de diversificación de la economía, había que concretar la estatización de recursos y capital (hasta entonces en manos de compañías estadounidenses) en conjunto con un proceso de reforma agraria para lograr un acceso más equitativo a la tierra.

6 Piero Gleijeses y Hope Shattered, The Guatemalan revolution and the United States 19441954, Princeton, Princeton University Press, 1991.

7 Susanne Jonas, "La democracia que sucumbió. La revolución guatemalteca de 1944 a 1954", en Tobis y Jonas, op. cit., pp. 83-110; Luis Cardoza y Aragón, La revolución guatemalteca, México, Cuadernos Americanos, 1955; José Arévalo, Guatemala, la democracia y el imperio, México, América Nueva, 1954.

8 Alfredo Guerra Borges, Guatemala: 60 años de bistoria económica, Guatemala, Serviprensa, 2011; Stephen Rabe, Eisenhower and Latin America. The Foreign Policy of Anticommunism, North Carolina, University of North Carolina Press, 1988; Jonas, op. cit. 
La Ley de la Reforma Agraria fue aprobada por el Congreso en junio de 1952 y preveía la "expropiación de extensiones de tierra mayores a cien hectáreas, en especial tierras ociosas". En enero de 1953 comenzó a aplicarse la ley y para junio de 1954 habían sido afectadas poco más de mil plantaciones que abarcaban un millón 200 mil hectáreas. Alrededor de 100 mil familias campesinas recibieron tierras. La UFCo tenía más de 220 mil hectáreas, de las que cultivaba sólo 15\%, por lo que se le expropiaron 160 mil hectáreas. ${ }^{?}$

Estas medidas recrudecieron la tensión con los sectores de la burguesía y terratenientes locales, pero también profundizaron las disputas por tierras en un nivel local, alimentando la contradicción entre el modo capitalista de producción y las formas de vida comunitarias. ${ }^{10}$ Así, fueron varios los sectores que se opusieron no sólo a la reforma agraria, sino a la tendencia "comunista" hacia la cual parecía inclinarse el gobierno de Arbenz, percepción que fue aumentando entre la oligarquía, comerciantes, profesionales y estudiantes, gracias al trabajo de la Iglesia católica anticomunista y la propaganda impulsada desde fuera, por la presión de los intereses públicos y privados estadounidenses.

Una parte de la contrarrevolución se organizó bajo el liderazgo de Castillo Armas, con el apoyo de gobiernos limítrofes como el de Anastasio Somoza y con el auspicio estadounidense. Desde la visión de los funcionarios estadounidenses, era inaceptable que se permitiera el "éxito" de un gobierno "aliado al comunismo". Incluso durante la presidencia de Arévalo se había planteado la preocupación de cómo operar en Guatemala. Finalmente, después de varias discusiones e intentos fallidos, Estados Unidos efectuó un plan basado en una "política de dos vías". ${ }^{11}$

La primera vía consistía en apelar a la Organización de Estados Americanos; es decir, "discutir" en un plano interamericano y decidir de modo multilateral las

9 Ibid., pp. 95 y 96.

10 Jim Handy, "Comunidad y revolución", en Guillermo Peláez Almengor [comp.], Guatemala 1944-1954: los rostros de un país, Guatemala, usAC/Centro de Estudios Urbanos y RegionalesUniversidad de Tromso, 1999.

${ }^{11}$ Bryce Wood, The dismantling of the Good Neighbor Policie, Austin, University of Texas Press, 1985, p. 162. 
acciones sobre Guatemala. La segunda vía, que se llevaría a cabo de manera simultánea a la primera, consistía en la organización de una operación encubierta organizada por la CIA para apoyar a los rebeldes liderados por Castillo Armas, que se encontraban en países limítrofes a Guatemala. Ambas estrategias se complementaban con mecanismos de presión económica.

La "vía diplomática" se materializó en la reunión que organizó Estados Unidos contra Guatemala, la X Conferencia Interamericana en Caracas, en marzo de 1954. En aquel momento, las "cartas estaban echadas", es decir, ya se respiraba en el aire la conspiración contra el gobierno guatemalteco, organizada desde dentro y desde fuera. En la conferencia se acusó a Guatemala de ser cabeza de playa de la Unión Soviética en América. ${ }^{12}$

La segunda vía se centraba en la intervención encubierta y militar debido a que, según los funcionarios estadounidenses, "El ejército [seis mil hombres] es el único elemento organizado en Guatemala capaz de alterar la situación política de forma rápida y decisiva". ${ }^{13}$ Fue en el marco de esta segunda opción que operó en especial la CiA. Entre los planes se incluía un operativo para perseguir y asesinar a "comunistas". ${ }^{14}$ También hubo un operativo fallido en 1952, la "Operación Fortune".

Luego de idas y venidas se gestó el PBSuccess (Operativo Éxito) que:

combinaría acciones psicológicas, económicas, diplomáticas y paramilitares [...]. La CIA hizo obligatorio el adiestramiento en guerra psicológica para los nuevos agentes [...] la operación dependía del impacto psicológico más que de fuerza militar real, aunque el éxito de este esfuerzo particular dependía también de la habilidad del esfuerzo de Castillo Armas para crear la impresión de que contaba con una fuerza militar muy sustancial. ${ }^{15}$

${ }^{12}$ Gregorio Selser, Cronología de las intervenciones extranjeras en América Latina, t. IV, México, CAMENA/Archivo Gregorio Selser/UACM, 2009.

13 United States Department of State, Foreign Relations, Guatemala 1952-1954, doc. 15.

14 Véase Gerald K. Haines, CIA and Guatemala Assassinations Proposals 1952-1954, the National Security Archive, 1995.

${ }^{15}$ Nick Cullather, Secret History: The cIA's classified account of its Operations in Guatemala, 19521954, The National Security Archive, California, Stanford University Press, 2006, pp. 41 y 79. 
A partir de la alianza entre el gobierno estadounidense, los mercenarios y los gobiernos de los países vecinos a Guatemala, sumada a la disidencia interna, se generó un proceso de desestabilización económica y política a través de la prensa y comunicados oficiales en contra del gobierno de Arbenz, un clima de confusión y de inestabilidad en el que nadie sabía a ciencia cierta qué podía suceder. El 18 de junio de 1954, columnas de mercenarios lideradas por Castillo Armas invadieron al país desde la frontera con Honduras. Al día siguiente de la invasión, el gobierno de Guatemala presentó una protesta formal contra la agresión hondureña y nicaragüense ante el Consejo de Seguridad de la onu. Pero Henry Cabot Lodge ${ }^{16}$ delegado estadounidense y presidente del Consejo de Seguridad determinó que no era un caso de agresión internacional sino de "guerra civil" interna y que, por eso, no era de incumbencia del Consejo de Seguridad..$^{17}$

En el momento de la invasión se realizaron ataques aéreos en el departamento de Alta Verapaz, e incluso en la ciudad capital. Arbenz acusó a Nicaragua, Honduras y Estados Unidos de fomentar la rebelión y declaró que "nuestro crimen es la reforma agraria contra las compañías imperialistas. Nuestro crimen es el de buscar patrióticamente la independencia económica". ${ }^{18}$ A fines de junio, Arbenz presentó su renuncia.

\section{LA MILITARIZACIÓN DE LA POLÍTICA Y LA SOCIEDAD}

En América Latina, en especial en el periodo de la Guerra Fría, se destaca la relación entre la militarización de la política (acceso de los militares a la esfera política formal o incremento de su influencia en la toma de decisión) y la reproducción de estructuras económico-sociales dependientes. Esto se vincula a que el proceso de integración del capitalismo posterior a 1945 incidió profundamente y de modo progresivo en el sector político militar del mundo oc-

\footnotetext{
${ }^{16}$ Henry Cabot Lodge poseía acciones en la ufco, véase Shlesinger y Kinzer, op. cit., p. 120.

${ }^{17}$ Jonas, op. cit., p. 101.

${ }_{18}$ Selser, op. cit.
} 
cidental por medio de un sistema de tratados y acuerdos militares ${ }^{19}$ y porque el crecimiento de la economía capitalista líder (la estadounidense) estaba basado en el complejo industrial-militar. ${ }^{20}$

Desde la visión de seguridad hemisférica estadounidense, el papel de América Latina y de las Fuerzas Armadas en el contexto de Guerra Fría era muy claro. Según documentos desclasificados, Estados Unidos debía garantizar su relación con América Latina:

a) la continua y creciente producción y entrega de materiales estratégicos esenciales; b) mantener un amplio espectro para el cambio político normal, [asegurando] el mantenimiento al interior de cada nación de la estabilidad políica y la seguridad interna para garantizar la protección de instalaciones de las cuales dependen la producción y entrega de materiales estratégicos; c) la cooperación mutua de todas las naciones de América Latina en apoyo de Estados Unidos; d) la protección de vías de comunicación vitales; e) la provisión, desarrollo, operación y protección de aquellas bases que puedan ser requeridas para el uso de Estados Unidos y para la protección de vías de comunicación; f) la protección coordinada de invasiones y redadas. ${ }^{21}$

Para lograr lo anterior, se esperaba que:

las Fuerzas Armadas de América Latina [fueran] capaces de mantener la seguridad al interior de sus propios territorios, incluyendo la prevención de disturbios revolucionarios, operaciones clandestinas enemigas, defensa contra ataques y sublevaciones, protección de las fuentes de materiales estratégicos, protección de las vías de comunicación y [garantizar la] seguridad local de las bases militares y suplementos militares. ${ }^{22}$

19 Theotonio Dos Santos, Socialismo o fascismo. El nuevo carácter de la dependencia y el dilema latinoamericano, Buenos Aires, Ediciones Periferia, 1972, pp. 121 y 122.

${ }^{20}$ Seymour Melman, El capitalismo del Pentágono: la economía de guerra, México, Siglo xxI, 1972; Harry Magdoff, "Militarismo e imperialismo", en Harry Magdoff, Theotonio Dos Santos, Richard Wolff y Paul Sweezy, Economía política del imperialismo, Buenos Aires, Ediciones Periferia, 1975.

${ }^{21}$ United States Department of State Foreign Relations, 1950, vol. I, p. 633.

22 Ibid., pp. 637 y 638. 
No obstante, no hicieron falta las indicaciones del Pentágono para que las Fuerzas Armadas dieran prioridad al enemigo interno, pues como sostiene Rouquié, ${ }^{23}$ eran los problemas internos, los peligros sociales o políticos locales los que históricamente habían suscitado la acción militar de los ejércitos latinoamericanos. Además de esta característica, desde mediados del siglo xIx, el ejército fungió en muchos países de la región como "punta de lanza" para la modernización, debido a su profesionalización, lo que contribuyó a que los militares se autodefinieran como los garantes de la integridad del Estado nación.

En especial a partir del siglo xx, estos procesos se vieron influenciados a su vez por las tensiones al interior de las Fuerzas Armadas entre generales (vinculados a políticas conservadoras) y jóvenes oficiales (en muchas ocasiones, asociados a lineamientos progresistas). Es por ello que también surgieron en el seno de las Fuerzas Armadas grupos que se unieron a reivindicaciones de otros sectores, defendiendo las medidas democráticas, tomando partido por los trabajadores, luchando por la representación y la justicia, imponiendo leyes sociales. ${ }^{24}$ En los casos en que estos grupos lograron influencia directa o indirecta en la esfera política formal, se plantearon distancias en la relación entre Fuerzas Armadas y la estructura político-económica dependiente. Asimismo, se generó una "mezcla" entre reivindicaciones civiles y modos de actuar militar que se conjugaron no sólo en los movimientos guerrilleros, sino en ideas y prácticas diversas sobre la democracia.

La vinculación entre el ejército y la estructura político-económica guatemalteca puede rastrearse desde el periodo de modernización impulsado por los gobiernos liberales, pues el ejército operó como institución de la Reforma Liberal de 1871 con el objetivo de defender dicho proceso orientado a la creación del Estado finca, consistente en la expropiación de las mejores tierras (de las comunidades indígenas y de la Iglesia) para destinarlas al cultivo de café, el banano y otros monocultivos por parte de la oligarquía terrateniente y los intereses económicos de los grupos dominantes. Así, "el ejército ha sido pieza fun-

${ }_{23}$ Alain Rouquié, El Estado militar en América Latina, Buenos Aires, EMECE, 1984, p. 114.

${ }^{24}$ Ibid., p. 128. 
damental para defender la gran propiedad privada, fundamentados bajo el discurso de la defensa de la soberanía nacional". 25

Igual que en tiempos de Ubico, cuando cada gobernador de los 22 departamentos era un general. Esto resultaba útil para mantener la estructura económico-política imperante, pues "con la militarización de funcionarios menores, según explicaban los marines estadounidenses, el presidente Ubico extiende su control militar sobre la vida cotidiana y cada pensamiento y acción del pueblo de Guatemala". ${ }^{26}$

Si bien las Fuerzas Armadas desempeñaron un papel protagónico en el derrocamiento de Ubico, no deben dejarse de lado las diferencias en los objetivos del levantamiento, ni las disputas entre viejos generales y los jóvenes oficiales. Según el coronel César Augusto Silva Girón:

Nosotros queríamos solamente detener a un hombre que se había vuelto loco en el poder [Ubico] [...] los generales también estaban escondiendo un plan conspirativo, también ellos estaban tras la silla presidencial y bien refugiados preparaban su golpe artero y traidor, pero [.. . ] su estrategia falló al menospreciar a los jóvenes oficiales que a última hora les comieron el mandado. ${ }^{27}$

Además, no todos los militares buscaban cambios estructurales, tal como lo expresaba el coronel Manuel de J. Pérez: "Confieso, pues, que no nos alzamos agitados por la bandera de la revolución, sino simplemente la de rebelión". ${ }^{28}$ Estas diferencias se hicieron visibles en la Asamblea Constituyente, en las discusiones referidas al rol que debía adquirir el ejército, y se reflejaron también en las presiones de ese sector para mantener privilegios por encima del poder civil. Como sostiene Móbil: "Aún cuando se hicieron públicas las pretensiones de algunos sectores de las Fuerzas Armadas no afines a la programática revolucionaria, los congresistas transigieron con aceptar algunas de las condiciones

25 uDEFEGUA-El Observador, Situación de defensoras y defensores de Derechos Humanos viviendo en el ámbito rural de Guatemala, Guatemala, 2010.

${ }^{26}$ Gleijeses y Shattered, op. cit., pp. 14 y 15.

27 José Antonio Móbil, La década revolucionaria 1944-1954, Guatemala, Serviprensa, 2010 (Col. Cuadernos de Octubre), p. 30.

${ }^{28}$ Ibid., p. 35. 
impuestas, ya que de no hacerlo, se llegó incluso a amenazar con impedir la toma de posesión del presidente electo [Arévalo]". ${ }^{29}$

Finalmente, en la Constitución de 1945 quedó estipulado que el ejército estaba para defender la integridad territorial de la nación, sostener el cumplimiento de la Constitución y el principio de la alternabilidad del presidente de la República, como institución esencialmente apolítica, profesional, obediente y no deliberante, garante de la seguridad interior y exterior, sujeto a las leyes y reglamentos militares.

Esta normativa ya planteaba al menos dos cuestiones controversiales. La primera, relativa a la "seguridad interior", función que seguía en manos del ejército. La segunda, es la premisa sobre el carácter "apolítico" de las Fuerzas Armadas, al presuponer que el "ser militar" estaría por encima, por ejemplo, de la pertenencia de clase.$^{30}$ En este sentido, en el marco del sistema capitalista, en particular en la fase de capitalismo monopólico asentado en el complejo industrial-militar durante la Guerra Fría, aquel que tuviera las armas, tendría de hecho el poder. Esto se complejizó hacia la década de 1960, cuando los sectores opuestos al estatu quo definieron que la única salida a los problemas estructurales de Guatemala se lograría por la vía armada (iniciada y liderada al principio por ex militares, como se verá más adelante).

Durante el gobierno de Arévalo hubo varios intentos de golpe por parte de ciertas facciones de las Fuerzas Armadas, incluso aunque el presidente tomó la precaución de sacar de sus puestos a muchos de los militares que se oponían a las reformas. ${ }^{31}$ Con la llegada de Arbenz a la presidencia (coronel muy respetado por sus compañeros de la Escuela Politécnica) los militares se vieron beneficiados por diferentes decisiones del gobierno orientadas a mejorar su

${ }^{29}$ Ibid., pp. 63 y 64.

${ }^{30}$ A este respecto vale la pena retomar a Lenin, cuando a principios de siglo xx advertía: "El ejército no puede ni debe ser neutral. No mezclar al ejército en la política es la consigna hipócrita de los sirvientes de la burguesía y el zarismo que, de hecho y en todo momento, han mezclado al ejército en la política reaccionaria, han convertido a los soldados en servidores de las centurias negras, en cómplices de la policía". Vladimir Lenin, La cuestión militar y el trabajo político en las Fuerzas Armadas, Buenos Aires, Independencia, 1970, p. 31.

31 Jim Handy, Gift of the devil. A history of Guatemala, Georgetown, South end Press, 1984, p. 133. 
estatus. Fue en este contexto que, según algunas visiones, se generó una división dentro del ejército, debido a la alianza entre los jóvenes oficiales de la escuela (representados por Arbenz) con los líderes sindicales por un lado, y los militares más viejos y de mayor rango (con posturas conservadoras) que habían sido educados y obtenido sus cargos durante el periodo ubiquista. Sin embargo, también se ha planteado que tal división no existió y que, en general, la mayoría de los militares se oponían a las premisas de la Revolución, a los sindicatos y a una economía dirigida. ${ }^{32}$

Ante este escenario, con el derrocamiento de Arbenz por los militares, se cuestiona la posibilidad de alcanzar una verdadera democracia con un ejército cada vez más poderoso. Cardoza y Aragón, protagonista del proceso revolucionario, intuyó o percibió que en la experiencia guatemalteca se estaban escribiendo los primeros renglones de la Doctrina de Seguridad Nacional (DSN): "De hecho, los militares tienen hoy el control de la mayor parte de nuestros países, en forma dictatorial. Y por medio de ellos, los Estados Unidos ya no necesitan desembarcar marinos: son su policía que cuida los monopolios y la línea política interna e internacional". ${ }^{33}$

\section{LAS FUERZAS ARMADAS EN LA POLÍTICA,}

\section{LA ESTRUCTURA ECONÓMICA Y LA CONTRAINSURGENCIA}

Las Fuerzas Armadas llegaron al poder político con Castillo Armas y el Movimiento de Liberación Nacional (MLN) creado en el marco del PBSucCEss. Desde aquel momento comenzó la reversión de los logros de la Revolución y se institucionalizó el anticomunismo como doctrina del miedo. Esto fue acompañado por regulaciones a favor del capital extranjero, en especial en materia de inversiones y actividades primario exportadoras y extractivas (petróleo y minería), en contradicción con las medidas nacionalistas establecidas por Arévalo y Ar-

32 Ibid., p. 134.

33 Cardoza, op. cit., pp. 49 y 50. 
benz. Existe una relación con el mencionado complejo industrial-militar estadounidense, que necesitaba recursos estratégicos y materias primas, así como mercados para expandir no solamente sus productos militares, sino su economía en general. De este modo, las "puertas abiertas" ${ }^{34}$ eran garantizadas por leyes como la Ley de Seguridad Mutua para proveer de armas y entrenamiento a otros países, así como asegurar las inversiones en el exterior. ${ }^{35}$ Guatemala constituyó un espacio clave en estos aspectos.

A partir del gobierno de Castillo Armas, las libertades y derechos políticos y económicos no existían de hecho ni de derecho, pues desde el Estado se institucionalizó la persecución. Sin embargo, la militarización de la política y la instauración de la doctrina del miedo operaron también como incentivo para el resurgimiento de revueltas y el fortalecimiento del Partido Guatemalteco del Trabajo (PGT), que - considerando la reversión de los procesos de la Revolución, la represión planteada desde el gobierno y el propio proceso de autocrítica-comenzó a inclinarse por la solución de la vía armada. ${ }^{36}$

Por otra parte, el asesinato del propio Castillo Armas (1957) puso a la vista la incapacidad y las divergencias al interior del movimiento contrarrevolucionario, e incluso al interior de las Fuerzas Armadas. En plena presidencia de Ydígoras Fuentes, se dio el levantamiento de jóvenes oficiales el 13 de noviembre de 1960. Algunas de las motivaciones eran la corrupción del gobierno en turno, la falta de atención a los militares más jóvenes y el "permiso" para que Estados Unidos organizara desde Guatemala la invasión a Playa Girón. Algunos de los involucrados en dicho levantamiento, como Yon Sosa y Turcios Lima, fueron los líderes de la guerrilla en los sesenta.

Esto se vincula con lo antes dicho sobre el papel fundamental de las Fuerzas Armadas no sólo como guardianas del estatu quo sino, contradictoriamente,

34 William Appleman Williams, Empire as a way of life, Nueva York, IG, 2007.

35 Jean P. Morray, "Estados Unidos y América Latina", en James Petras y Maurice Zeitlin (comps.), América Latina: ireforma o revolución?, Buenos Aires, Tiempo Contemporáneo, 1970, pp. 97-116.

36 Carlos Figueroa Ibarra, "Violencia política e insurgencia armada en Guatemala 1954-1995", en Carlos Figueroa Ibarra [comp.], América Latina. Violencia y miseria en el crepúsculo del siglo, Puebla, BuAP-ALas, 1996, p. 92. 
como generadoras de grupos capaces de impulsar acciones "rebeldes": los líderes militares sublevados no se autodefinieron como revolucionarios, sino hasta que unieron sus fuerzas al PGT. ${ }^{37}$ La sublevación de 1960 fue el inicio de otros levantamientos (como el de Concuá en octubre de 1962) y de una serie de movilizaciones sociales y políticas, como las jornadas de marzo y abril de 1962, impulsadas por estudiantes de secundaria, muchos de los cuales integrarían los movimientos guerrilleros a mediados de los sesenta y setenta.

Un dato elemental es que, también hacia fines de 1960, el ejército realizaba programas de "acción civil" que luego fueron sistematizados como parte de la asistencia estadounidense brindada a través de la Alianza para el Progreso, en particular a través de la Agencia para el Desarrollo Internacional (AID, por sus siglas en inglés). Esta agencia, además de ocuparse de la "asistencia para el desarrollo" formaba parte de un programa conjunto para definir las armas, tácticas y fuerzas que debían recomendarse para el control de revueltas violentas, así como los medios para asegurar los stocks adecuados de equipos con la finalidad de controlar la insurgencia y hallar la forma de proveer las armas apropiadas para la policía. ${ }^{38}$

La acción civil era el "uso de fuerzas militares locales en proyectos útiles para la población en todos los niveles, como educación, entrenamiento, obras públicas, transporte, comunicaciones, salud, y otros que contribuyan al desarrollo económico y social, que servirán también para mejorar el lugar de los militares en la población". ${ }^{39}$ Hoy se podría hablar de esto como el softpower de la Guerra Fría en América Latina, junto con las "operaciones psicológicas" 40

El aparato contrainsurgente se legalizó con la Constitución de 1965 (en el marco de un gobierno militar) y se exacerbó durante el gobierno "civil" de Méndez Montenegro, que desde un primer momento había cedido a las presiones

37 Ibid., p. 94.

${ }^{38}$ United States Department of State, Foreign Relations, 1961-1963, vol. XII, doc. 90.

39 Andrea Brown, "The vietnamization of Guatemala. US counterinsurgency programs", en Tobis y Jonas, op. cit., p. 194.

${ }^{40}$ Véase Joseph Nye, "The decline of America's soft Power", en Foreign Affair's, Nueva York, mayo-junio de 2004. En http://www.foreignaffairs.com/articles/59888/joseph-s-nye-jr/the-decline-of-americas-soft-power. 
militares para acceder a su cargo. ${ }^{41}$ La ofensiva contrainsurgente combinaba la citada acción cívica con el desarrollo de una campaña genocida, principalmente en el nororiente del país, puesto que allí se encontraba asentada la insurgencia. De hecho, estos programas buscaban mostrar la "cara democrática y progresista" de las Fuerzas Armadas y pasaron a formar parte de la DSN, dentro del rubro "Operaciones de Asuntos Civiles" (que hasta 1969 se denominaron como Operaciones de Estabilidad) que consistían en intervenir en las actividades de "modernización económica y progreso social" establecidas en los programas de desarrollo social y económico nacional cívico. ${ }^{42}$

Esto permitió implementar una gran ola de terror - la segunda después de 1954 - iniciada a fines de 1966, y que concluyó aproximadamente en $1971 .^{43}$ Vale agregar que entre 1956 y 1963 la asistencia de Estados Unidos a Guatemala aumentó diez veces y que entre 1963 y 1969, 29\% de la asistencia militar estadounidense se dirigió a Guatemala. En 1965, la ayuda alcanzó un promedio de 538 dólares por soldado. ${ }^{44}$ Así fue que se materializó la Alianza para el Progreso en Guatemala, que consistía, más allá del discurso oficial, en planes de "asistencia para el desarrollo y democracia” acompañados por el entrenamiento para la contrainsurgencia, con el fin de evitar otra Cuba. ${ }^{45}$

Este entrenamiento y la "profesionalización" de los militares tuvieron un efecto importante en el plano económico-político, pues cristalizó en la búsqueda de un ascenso en la escala socioeconómica por parte de los oficiales, pues

Al volver a Guatemala [después de su entrenamiento en el exterior], sus nuevas aspiraciones los impulsan a buscar fuentes de ingresos adicionales, sea a través de un puesto civil, sea en el sector privado, lo cual explica la existencia de numerosos oficiales-hombre de negocios y sobre todo grandes propietarios de tie-

${ }^{41}$ Comisión Para el Esclarecimiento Histórico, Memoria del Silencio, Guatemala. En http://shr.aaas.org/guatemala/ceh/mds/spanish/toc.html, p. 125.

${ }^{42}$ Jorge Tapia Valdés, El terrorismo de Estado. La doctrina de la seguridad nacional en el Cono Sur, México, Nueva Imagen, 1980.

43 Figueroa, op. cit., p. 96.

${ }^{44}$ Handy, Gift of the devil..., p. 156.

45 Silvina M. Romano, "Obama y la Alianza para el Progreso: la retórica del desarrollo y la práctica de la 'seguridad interna”', en Revista Izquierda, núm. 16, Bogotá, 2011, pp. 62-69. 
rras abiertas a la colonización por el Estado. Estas diferencias en cuanto a nivel de ingresos guardan relación con la participación de los militares en el mundo de los negocios, muy común en los países donde el ejército ha sufrido con mayor fuerza la influencia de Estados Unidos. ${ }^{46}$

Esto se combinó de hecho con el impulso a la isi y de los grupos empresariales, que comenzaron a ocupar cada vez mayor espacio en la política. ${ }^{47}$

También es a partir de esta reorganización de la seguridad interna que se busca una coordinación a nivel regional, al tiempo en que se consolidaba la integración económica en el Mercado Común Centroamericano. Así se conformó el Consejo de Defensa Centroamericano (CONDECA) en 1964, que tuvo como una de sus actividades principales la de centralizar los operativos de inteligencia contra la subversión; ${ }^{48}$ un antecedente de la Operación Cóndor, que se extendería, hasta los años ochenta, desde el Cono Sur hasta la guerrilla de América Central. ${ }^{49}$

\section{RESISTENCIA, TIERRA ARRASADA Y PROFUNDIZACIÓN DE LA DESIGUALDAD}

Entre mediados y finales de los sesenta se logró, en cierta medida, desarticular a la guerrilla, a principios de los setenta, 22 de los líderes del PGT habían sido asesinados. Para ese entonces, $2.1 \%$ de los propietarios detentaba $62 \%$ de la tierra cultivable; 87\% era dueño de 19\% de la tierra; 21\% eran "señores exportadores" que poseían latifundios y 84\% eran agricultores de subsistencia que, en verdad, no lograban "subsistir" sin trabajar en las haciendas de los grandes terratenientes. ${ }^{50}$

Las condiciones políticas y la estructura desigual contribuyeron nuevamente a la rearticulación de la izquierda. Comenzaron a hacerse visibles las manifestaciones y los movimientos sociales. Se destaca la huelga de maestros de 1973, a

\footnotetext{
46 Rouquié, op. cit., p. 164.

47 Torres Rivas, op. cit., pp. 102 y 103.

48 Jonas y Tobis, op. cit., p. 205.

49 Stella Calloni, Operación Cóndor, pacto criminal, México, La Jornada, 2001.

50 Brown, "Tierra de unos cuantos...
} 
la que siguieron las de otros sectores laborales que salieron a las calles con reivindicaciones políticas y económicas. ${ }^{51}$ También se sumaron los conflictos de trabajadores con el capital extranjero: los de Coca-Cola (1975-1980), de Acricasa, filial textil de una transnacional japonesa (1977-1980), los de las minas de San Ildefonso Ixtahuacan (noviembre de 1977), los de las minas del Exmibal (noviembre de 1979), y los de las represas hidroeléctricas de Aguacapa y de Chixoy. Ante esta movilización del sector laboral se profundizó la represión por parte de militares y paramilitares, de estos últimos, muchos fueron contratados tanto por el sector privado local (como el Comité de Actividades Comerciales Industriales y Financieras) así como por las empresas extranjeras. ${ }^{52}$ Un ejemplo de la política antisindical impulsada desde el Estado fue la eliminación sistemática de los secretarios generales y miembros ejecutivos del sindicato de CocaCola, clave en el movimiento entre 1970 y $1980 .{ }^{53}$

Mientras tanto, el movimiento revolucionario fue asentando sus bases en las zonas rurales. Para fines de los setenta y principios de los ochenta, el Ejército Guerrillero de los Pobres (EGP) ya contaba con una organización sustantiva; la Organización del Pueblo en Armas (ORPA) ya había salido a la luz y también mostraba un importante nivel organizativo. Todo esto pudo acontecer en el contexto del estallido revolucionario en Centroamérica, a partir del asesinato de Chamorro y el triunfo de la Revolución sandinista en Nicaragua. ${ }^{54}$

Hacia 1980, el analfabetismo urbano en Guatemala era de 70\% y el rural ascendía a 96\%; la mortalidad infantil era de 81 por cada mil niños nacidos vivos; había dos médicos por cada 16 mil habitantes; 60\% de las viviendas urbanas no tenía servicios sanitarios básicos y sólo 40\% tenía acceso a agua potable. Estos datos se relacionan con el hecho de que 31\% de la población poseía $72 \%$ del suelo cultivable..$^{55}$

${ }^{51}$ Yvone Le Bot, "Guatemala: luchas sociales ante un horizonte de guerra 1973-1982", en Cuadernos Políticos, núm. 35, México, octubre-diciembre de 1983, p. 8.

52 Ibid., pp. 9 y 10.

53 Comisión para el Esclarecimiento Histórico, op. cit., p. 29.

${ }^{4}$ Figueroa Ibarra, op. cit., p. 101.

55 Jacobo Vargas Fronda, Guatemala: sus recursos naturales, el militarismo y el imperialismo, México, Claves Latinoamericanas, 1984, pp. 25 y 26. 
Además, si bien hubo un periodo de impulso a la industrialización durante la década de 1960, en especial en el marco del Mercado Común Centroamericano, la economía seguía asentada en la exportación de uno o dos productos alimenticios, a lo que se sumó la extracción de minerales, en particular de níquel, producto esencial en la industria armamentista. Con la reforma de la constitución y del Código de minería de 1965 se favoreció a Exmibal (empresa transnacional Exploraciones y Explotaciones Mineras de Izabal) a la que se le otorgó una concesión por 40 años para extraer níquel, cobalto, cromo y cobre de la mina Niquegua. ${ }^{56}$

El gobierno militar de Fernando Romeo Lucas García (1978-1982) aumentó la inversión pública en 41\% para obras de gran envergadura, y para pagarlo recurrió al endeudamiento interno, restringiendo los créditos para el sector privado. ${ }^{57}$ Sería importante revisar, sin embargo, quiénes del sector privado participaron y salieron beneficiados de tales proyectos de obras públicas. Para 1982 se redujo en niveles históricos la recaudación de ingresos fiscales, sumado al contexto de crisis internacional para los países primario-exportadores, y para los que habían sido acreedores de petrodólares.

El fuerte de Lucas García fue la contrainsurgencia, práctica que para ese entonces se había extendido por toda América Central, debido al avance de la guerrilla. El establishment estadounidense lo denominó como "guerra de baja intensidad" (GBI), que se basaba en la contrainsurgencia, la reversión de procesos y el antiterrorismo. ${ }^{58}$ Para cumplir con estos ejes, uno de los componentes era el entrenamiento de Fuerzas de Operación Especiales, "entrenadas para operar como guerrillas y para realizar actividades clandestinas". ${ }^{59}$ De hecho, Guatemala era el único país de América Central que había logrado institucionalizar estas fuerzas desde mediados de 1970, pues la Escuela de Comandos que formaba Kaibiles se creó en 1974, bajo iniciativa del mayor Pablo Nuila Hub. De los

\footnotetext{
56 Jonas y Tobis, op. cit., p. 157.

57 Guerra Borges, op. cit., pp. 127 y 128.

${ }^{58}$ Lilia Bermúdez, Guerra de baja intensidad, México, Siglo xxI, 1987, p. 85.

59 Ibid., pp. 91-93.
} 
cuatro primeros oficiales instructores, tres se habían formado en la Escuela de las Américas. Debe destacarse que hacia finales de aquella década se llevó a cabo una kaibilización de las Fuerzas Armadas guatemaltecas, lo cual explica en parte el grado de violencia y las técnicas de contrainsurgencia feroces implementadas en los ochenta. ${ }^{60}$ Tanto el gobierno de García como sus sucesores aprovecharon las fuerzas especiales y el apoyo de Estados Unidos en la GBI.

Se llevó a cabo un reajuste en los mecanismos contrainsurgentes, cuando los "oficiales jóvenes", liderados por Ríos Montt, perpetraran un golpe de Estado e instauraron el "Plan Nacional de Seguridad y Desarrollo" que incluía entre sus premisas:

aumentar los efectivos militares, particularmente el número de comandantes para apoyar las Unidades de Autodefensa Civil (1) negarles a los subversivos el acceso a la población que constituía su apoyo político-social (2) rescatar a quienes estaban en las Fuerzas Irregulares Locales, neutralizando o eliminando a aquellos que no quisieran integrarse a la vida normal; (3) eliminar las Unidades Militares Permanentes (de la subversión). ${ }^{61}$

La nueva propuesta de los "jóvenes oficiales" era acompañar al terror contrainsurgente con medidas políticas de carácter nacional (no solamente de carácter comunitario como sucedía con la "acción cívica") para recuperar el consenso político alrededor del Estado. Se buscó desmontar la "dictadura militar" y sustituirla por un gobierno civil, pero esta suerte de modernización estatal que los militares y los ideólogos de la dictadura hicieron aparecer como "transición a la democracia", no implicó el desmantelamiento del terrorismo de Estado. ${ }^{62}$ Este giro abrió la puerta a una sociedad militarizada con fachada democrática, lo que a la larga operó como factor de erosión constante de la democracia.

${ }^{60}$ Manolo Vela Castañeda, Peritaje histórico social, el caso: la masacre de las Dos Erres, Guatemala, FLACSO, 2010, pp. 28-32.

${ }^{61}$ Jennifer Schirmer, Las intimidades del proyecto político militar en Guatemala, Guatemala, FLACSO, 1998, p. 150.

${ }^{62}$ Figueroa Ibarra, op. cit., p. 103. 
En el marco de este nuevo plan nacional y continuando con lo iniciado durante la gestión de Lucas García, se implementó la técnica de tierra o aldea arrasada, para "quitarle el agua al pez"; es decir, quitarle el apoyo social a la guerrilla. Este proceso incluyó tres etapas: la primera, orientada a la represión selectiva y relevamiento de información para seleccionar a las "zonas rojas"; la segunda, destinada a no dejar señales de vida en tales zonas (a esta etapa corresponden "Victoria '82", "Firmeza '83" y "Operación Sofía"); la última etapa, a partir de 1984, articuló la represión y formas de reorganización y control de la población sobreviviente para impedir el surgimiento de formas de vida que pusieran en peligro el sistema excluyente que convenía a la oligarquía, por ejemplo el plan "Estabilidad nacional ' 85 ". 63

Así, considerando solamente los 17 meses del gobierno de Ríos Montt, fueron asesinados más de 16 mil guatemaltecos, salieron del país más de 90 mil refugiados - principalmente a México- y se desplazaron internamente cerca de un millón de personas. ${ }^{64}$ El subsecretario de Estado norteamericano para los Derechos Humanos, Elliott Abrams, sostenía que la violencia y los refugiados eran el "precio de la estabilidad" ${ }^{65}$ Es interesante esta alusión a la "estabilidad", pues era el objetivo del nuevo plan nacional de las Fuerzas Armadas "en democracia". Lo importante es que esta fachada civil de la institucionalización de un Estado contrainsurgente, además de desgarrar el tejido social en las comunidades, generó una desconfianza y rechazo por el Estado en sí mismo, tendencia que pervive hasta la actualidad. Esto es casi inevitable si se considera el saldo del conflicto interno: 200 mil personas asesinadas o desaparecidas; un millón y medio de desplazados y 200 mil refugiados en México y otros tantos en Belice.

${ }^{63}$ Sofía Duyos, "Plan de Operaciones 'Sofía': fuerzas especiales del ejército destinadas a una misión de exterminio", en Plan de Operaciones Sofía, Confederación Sindical de Comisiones Obreras, Guatemala, 2011, p. 9.

${ }^{64}$ Figueroa Ibarra, op. cit.

65 Antonio García, "Breves notas sobre un largo conflicto armado", en Plan de Operaciones Sofía, Confederación Sindical de Comisiones Obreras, Guatemala, 2011, p. 3. 


\section{ACUERDOS DE PAZ Y DEMOCRACIA NEOLIBERAL}

A mediados de la década de 1990 se firmaron los Acuerdos de Paz, que fueron los más completos de la región, puesto que incorporaron aspectos vinculados a la redistribución de los medios de producción, el respeto a los derechos humanos y la autodeterminación de los pueblos indígenas, así como la desmilitarización de las comunidades. ${ }^{66}$

Sin embargo, se avanzó más en la inclusión política que en la inclusión económica, como sucedió en otras democracias logradas a partir de mediados de los ochenta en buena parte de América Latina. Esta nueva oleada de democracias llegó de la mano del neoliberalismo y del "ajuste estructural", como forma de "estabilizar" la economía, la sociedad y la política (sin recurrir a las Fuerzas Armadas). Entonces, junto con la democracia, se impulsó la apertura indiscriminada de los mercados y la privatización de las economías, como el único camino "al desarrollo", para pagar el endeudamiento externo y lograr insertarse del "mejor modo posible" en el mercado internacional. ${ }^{67}$ Esto amplió la distancia entre la democracia formal y la democracia sustantiva, y se afectó la legitimidad de esta forma de gobierno.

En el caso de Guatemala, con el advenimiento de la democracia (1986), no puede decirse que las características de Estado contrainsurgente hayan sido superadas. Justamente, como lo plantea Jonas, la enorme escalada de violencia en la Guatemala de los noventa se vinculaba a que la clase dominante nunca estuvo dispuesta a otorgar concesiones "mínimas" a las mayorías. Así, la minoría sigue necesitando un "Estado policía que proteja las libertades y la propiedad" ${ }^{6}$

Vale señalar que este proceso de acumulación no persiste aislado, sino que permanece gracias a un sistema internacional que lo legaliza y legitima: "Los tecnócratas neoconservadores y las Instituciones Financieras Internacionales invo-

${ }^{66}$ UDEFEGUA, op. cit., p. 25.

${ }^{67}$ Borón, op. cit.; Ciska Raventós [comp.], Innovación democrática el Sur. Participación y representación en Asia, África y América Latina, Buenos Aires, CLAcso, 2008 (Col. Sur-Sur).

${ }^{68}$ David Martínez-Amador y Robinson Salazar Pérez, "Guatemala entre rosas y piedras: lecciones del escándalo Rosenberg", en Ignacio Núñez Medina [coord.], Centroamérica: democracia, militarismo y conflictos sociales en el siglo XXI, Buenos Aires, El Aleph-Insumisos, 2010, p. 55. 
lucradas de lleno en el proceso de paz guatemalteco, impusieron sus demandas frente a las reformas sustantivas para lograr democracia y justicia social". ${ }^{69}$

Los resultados de la permanencia de la estructura de poder son contundentes. Según el Instituto Nacional de Estadísticas, en 2006, aproximadamente la mitad de la población guatemalteca se encontraba por debajo de la línea de pobreza. ${ }^{70}$ Además, $74.8 \%$ de estos pobres son indígenas. También se sabe que desde inicios del siglo xxi, Guatemala es uno de los países con índices más altos de mortalidad en niños menores a cinco años, y que uno de cada cinco niños sufre de desnutrición. ${ }^{71}$ De hecho, la desnutrición afectaba 14\% de la población guatemalteca en 1992, 17\% en 1997 y 16\% en $2006 .^{72}$

A lo anterior se suma la concentración de la propiedad de la tierra. Según el censo agropecuario de 2003, "92.06\% de las y los pequeños productores únicamente cultivan $21.86 \%$ de la superficie, mientras $1.86 \%$ de los productores comerciales ocupan 56.59\% de la superficie. Existen 47 fincas de 3700 hectáreas o más, mientras $90 \%$ de los productores sobreviven con un promedio de una hectárea". 73

Esta situación en la tenencia de la tierra adquiere una importancia crucial, pues el lugar de Guatemala en la actual división internacional del trabajo refuerza las inversiones en actividades como producción de alimentos, minería y generación de energía. Para el gobierno, en coordinación con organismos internacionales, se plantea que la electricidad, la minería y la construcción de carreteras resultan sectores muy rentables para la inversión extranjera directa. ${ }^{74}$

${ }^{69}$ Kevin L. O'Neill y Thomas Kendron [ed.], Securing the city. Neoliberalism, space, and insecurity in Guatemala, Durham, Duke University Press, 2011, p. 9.

${ }^{70}$ Instituto Nacional de Estadística de Guatemala, Encuesta general de condiciones de vida 2006. En http://www.ine.gob.gt/index.php/demografia-y-poblacion/42-demografiaypoblacion /64-encovi, 2006.

${ }^{71}$ unDP-OEA, Nuestra democracia, 2010. En http://www.nuestrademocracia.org/pdf/nuestra democracia.pdf, p. 91.

72 World Bank, World Development Indicators, 1985, CD-ROM.

73 Carlos Barreda, "Guatemala: crecimiento económico, pobreza y redistribución", 2007. En http://www.albedrio.org/htm/documentos/CarlosBarreda-001.pdf.

${ }^{74}$ UnCTAD, Análisis de la política de la inversión en Guatemala, Nueva York y Ginebra, onu, 2011. En unctad.org/es/docs/diaepcb201009_sp.pdf, p. 71. 
Sin embargo, este tipo de actividades pueden llevar a una descapitalización progresiva, a la vez que generan un daño (la mayoría de las veces irreparable) para las comunidades cuyos territorios son saqueados y apropiados por las empresas vinculadas a la inversión. Muchas comunidades se han organizado para hacer cumplir la letra de los Acuerdos de Paz llevando a cabo, por ejemplo, consultas para decidir sobre la instalación o no de "megaproyectos" en sus territorios. Estos referéndums dan cuenta de los avances en las prácticas democráticas, pero también se han realizado bajo la presión de la presencia de militares. A su vez, el gobierno no tiene en cuenta el resultado de tales opiniones comunitarias, al categorizarlas como "no vinculantes". Es como si el gobierno dijera "qué bonito tu acto, pero no es vinculante para nosotros, no afecta de ninguna manera lo que queremos hacer". ${ }^{75}$

\section{VIOLENCIA Y SEGURIDAD ¿QUUIÉN ES EL ENEMIGO INTERNO?}

La Guatemala de hoy, junto con los indicadores de pobreza antes mencionados, presenta uno de los niveles de violencia más altos del continente. Si se consideran los homicidios perpetrados cada 100 mil habitantes, Guatemala alcanzó un índice de 25.8 en 2000, que se incrementó a 48 en el año $2008 .^{76}$ En el año 2009 fueron asesinadas 6500 personas. ${ }^{77}$

En este contexto, hay un terreno cada vez más fértil para el narcotráfico, el tráfico de armas y el "crimen organizado", que a su vez ha generado un nuevo nicho de mercado, el "negocio de la seguridad" ${ }^{78}$ Esto se percibe a través de algunos datos sobre la seguridad privada en Guatemala: en 2000 había 68 agen-

75 Entrevista realizada a integrante de la Network in Solidarity with the People of Guatemala (NISGUA), Guatemala, 23 de marzo, 2012.

76 UNDP-OEA, op. cit., p. 84.

77 Dina Fernández, "Living dangerously. Portraits of daily violence", en Harvard Review of Latin America, vol. 10, núm. 1, 2010, pp. 39 y 40.

${ }^{78}$ Kedron Thomas y Kevin Lewis O'Neill, "Securing the city. The politics and business of postwar security", en Harvard Review of Latin America, vol. 10, núm. 1, 2010. 
cias de seguridad registradas; en 2006 esta cifra subió a 128, con 28 mil guardias, más 60 mil guardias que trabajaban para agencias no autorizadas. A su vez, parece que la industria de la seguridad mueve más de ocho millones de dólares al año. ${ }^{79}$

Las décadas de violencia y pobreza han profundizado la inseguridad cotidiana, generando imaginarios y conductas que tienden a criminalizar la pobreza. Esto condujo a una mayor segregación y a la reducción del espectro de las causas de la violencia urbana, proyectando la culpa en las "bandas urbanas" (como "las maras") como principales e incluso únicos culpables de la violencia. ${ }^{80}$ Tales percepciones desatienden las causas y condiciones histórico-estructurales respondiendo a una necesidad (especialmente del gobierno) de encontrar un "chivo expiatorio".

Este panorama se corresponde con la neoliberalización y privatización de la violencia en Guatemala, ${ }^{81}$ que se refleja, también, en el financiamiento externo bilateral, multilateral, público y privado, para "atacar" los problemas de seguridad. Por ejemplo, la "seguridad ciudadana" es uno de los ámbitos de mayor preocupación de organismos internacionales, Organizaciones no Gubernamentales (ONG), fundaciones y del gobierno de Estados Unidos. La usAiD es una de las organizaciones que trabaja en la seguridad ciudadana para contrarrestar a las "bandas de delincuentes juveniles" como "las maras". ${ }^{2}$

79 Avery Dickins de Girón, "The security guard industry in Guatemala", en Kedron Thomas y Kevin Lewis O'Neill [eds.], Securing the city. Neoliberalism, space, and insecurity in Postwar Guatemala, Durham, Duke University Press, 2011, pp. 104, 110.

${ }^{80}$ O'Neil y Thomas, op. cit., p. 3.

${ }^{81}$ Peter Benson, Kendron Thomas y Edward Fischer, "Guatemalas's New Violence as Structural Violence", en Thomas y O'Neill , op. cit., p. 141.

82 Véanse Arturo Valenzuela, "Sobre la relación de Estados Unidos con el Hemisferio Occidental", Comparecencia ante la subcomisión del Hemisferio Occidental en la Comisión de Asuntos Exteriores de la Cámara de Representantes, Washington, D. C., 13 de abril, 2011; Robinson Pérez Salazar, "Paramilitarización de las pandillas en Centroamérica", en Ignacio Medina Núñez [coord.], Centroamérica: democracia, militarismo y conflictos en el siglo XXI, Buenos Aires, Ediciones Insumisos Latinoamericanos/El Aleph, 2010. 
En un informe elaborado por el Banco Interamericano de Desarrollo (BID) y la Oficina de Washington para Latinoamérica (wola, por sus siglas en inglés), ${ }^{83}$ se enumeran y analizan los diferentes campos de intervención de la asistencia para la seguridad ciudadana en los países de América Central entre 2009 y 2010: el fortalecimiento institucional, la prevención, la rehabilitación y el apoyo al combate contra el crimen organizado. Estados Unidos es el mayor "donante" en todos los rubros, pero la brecha más amplia respecto a las aportaciones de otros organismos es en el rubro de "apoyo al combate del crimen organizado". Estados Unidos aporta 171 millones de dólares, mientras que el organismo que le sigue, la onu, otorga 17 millones. En cambio, en rubros como la "prevención de la violencia”, Estados Unidos ha aportado 65 millones y el gobierno español 43 millones.

Lo interesante aquí es revisar, entonces, lo que está implicado en el apoyo al combate al crimen organizado: "proyectos cuyo objetivo y actividades están dirigidas a fortalecer a los países para combatir el tráfico de drogas; tráfico de personas; tráfico de inmigrantes; lavado de activos; terrorismo (incluye: investigación criminal; unidades de élite; inteligencia operativa; control de fronteras)" " ${ }^{84}$ Así, el combate contra el "crimen organizado" implica un importante rol de las fuerzas policiales y en especial las militares, incluyendo los comandos o unidades de élite.

Esto se enmarca en las acciones destinadas a fortalecer el softpower en la estrategia de política exterior estadounidense, a la vez que coincide con el nuevo impulso al cuarto pilar de la Iniciativa Mérida, el de "construir comunidades fuertes". Además, a través de la Iniciativa Regional de Seguridad para América Central (y con financiamiento del BID) se busca implantar el "modelo colombiano" para instituir una reforma policial en el combate al "crimen organizado". 85

${ }^{83}$ Kariela Villamar, Adriana Beltrán y Pablo González, "Mapeo de las intervenciones en seguridad ciudadana en Centroamérica financiadas por la Cooperación Internacional", en Banco Interamericano de Desarrollo y Washington Office on Latin America, Washington, 2011.

${ }^{84}$ Ibid., p. 45.

85 Sobre las consecuencias del Plan Colombia y la Iniciativa Mérida véase Gian Carlo Delgado Ramos y Silvina M. Romano, "Political-Economic Factors in U.S. Foreign Policy: The Colombia Plan, the Mérida Initiative, and the Obama Administration", en Latin American Perspectives, vol. 38, núm. 4, Riverside, Estados Unidos, julio de 2011, pp. 93-108. 
En este punto, es fundamental señalar que Estados Unidos se ha encargado hasta la actualidad del entrenamiento de las tropas de élite en Guatemala (las Fuerzas de Operaciones Especiales, como los Kaibiles) implicados en abuso a derechos humanos e involucrados en los escuadrones de la muerte. ${ }^{86}$ Por otra parte, hay información que sostiene que el cártel de los Zetas ha contratado Kaibiles para engrosar sus filas, ${ }^{87}$ aspecto que es más que sugerente considerando que los grupos de élite son en especial entrenados para enfrentar al narcotráfico. Conviene recordar también que parte de los Zetas pertenecía a tropas de élite mexicanas entrenadas por militares estadounidenses contra la narcoinsurgencia durante los noventa. ${ }^{88}$ Como puede verse, el panorama es sumamente complicado, pues vincula a las tropas de élite con las Fuerzas Armadas estadounidenses y con cárteles narcotraficantes. Se complejiza aún más si se considera el aumento de la asistencia contra la narcoinsurgencia en los últimos años.

Como corolario, recientemente se ha informado de modo oficial que la Drug Enforcement Administration (DEA) está actuando en operativos en América Central, pues los gobiernos de la región necesitan ayuda en la lucha contra los cárteles: "Uno tiene que tener capacidades y equipos especiales para operar efectivamente y con seguridad en ambientes como éste. La DEA trabaja hombro con hombro y en la línea de fuego con sus contrapartes en las naciones anfitrionas", dijo Michael A. Braun, ex jefe de operaciones de la agencia y uno de los diseñadores del programa. Parece que la DEA ya efectuó 15 operativos en la región, aunque se asegura que hasta el momento se ha tratado "sólo de entrenamiento". 89

En el plan de lucha contra el narcotráfico iniciado por Álvaro Colom, el narcotráfico deviene en otro de los ambiguos enemigos internos. Además, durante su gobierno se dieron importantes avances en la lucha contra la impunidad,

${ }^{86}$ Guatemala Solidarity, "Trial for Guatemala Massacre Concludes, but U.S. Military Aid Continues", 2011. En http://www.guatemalasolidarity.org.uk/?q= content/trial-guatemala-massacreconcludes-us-military-aid-continues.

87 "Confirman presencia Kaibiles", en El Universal, 31 de octubre, 2005. En http://www2.eluniversal.com.mx/pls/impreso/noticia.html?id nota $=131520 \&$ tabla $=$ nacion.

${ }^{88}$ George Withers, Lucila Santos y Adam Isacson, "Preach What You Practice: The Separation of Military and Police Roles in the Americas", en wola, noviembre de 2010.

${ }^{89}$ The New York Times, 6 de noviembre, 2011. 
pero también se vivió lo que puede llamarse la "cero información" y "cero consulta" a las comunidades indígenas en lo relativo a la explotación de recursos naturales en territorios indígenas a favor de las transnacionales. ${ }^{90}$

Por ejemplo, el Departamento de Quiche, desde la década de 1960, junto a otros departamentos de la cordillera central, es considerado como un reservorio de recursos energéticos por parte del capital nacional y extranjero. Con el objetivo de generar mejores condiciones para la inversión nacional y extranjera, el gobierno guatemalteco emitió el Decreto 48-97 (un año después de los Acuerdos de Paz), en el que se establece que $99 \%$ de las ganancias por actividades extractivas va directo a las empresas nacionales y transnacionales. ${ }^{91}$

De hecho, después de los Acuerdos, se dieron varios procesos de resistencia frente a megaproyectos y transnacionales, unificados, por ejemplo, en el Consejo de los Pueblos de Occidente (CPO), que aglutina la lucha y resistencia en defensa de la vida y los bienes naturales en varios departamentos del país. Uno de los grupos que conforman dicha plataforma, el Frente de Resistencia contra la Explotación de los Recursos Naturales (Frena), es uno de los que ha experimentado mayor represión, y da cuenta de la vulnerabilidad a la que se enfrentan los y las defensoras de derechos humanos. Entre 2009 y 2010 fueron asesinados los siguientes líderes comunitarios vinculados a Frena: Víctor Gálvez (octubre 2009), Evelinda Reyes (enero 2010) y Pedro Antonio García (enero 2010), secretario del Sindicato de Trabajadores Municipales de Malacatán. ${ }^{92}$

En un informe sobre la situación en América Central, se relata que en agosto de 2011, 300 campesinos de Nueva Esperanza fueron expulsados de las tierras que les pertenecían. El ministro del Interior justificó lo sucedido argumentando que esas familias estaban apoyando a narcotraficantes. Nueva Esperanza está emplazada en una zona disputada para diversos megaproyectos, donde las empresas cuentan con seguridad privada estrechamente vinculada a los militares y

\footnotetext{
90 Pablo Ceto, "Un nuevo amanecer. La Guatemala plural y los Acuerdos de Paz frente al racismo y la debilidad actual del Estado", en Plan de Operaciones Sofía, Confederación Sindical de Comisiones Obreras, Guatemala, 2011, p. 33.

${ }^{91}$ UdEFEguA, op. cit., pp. 32, 33 y 39.

92 Ibid., pp. 48-59.
} 
la policía. ${ }^{93}$ Entonces, ¿a quiénes se está combatiendo? ¿Al narcotráfico o a la protesta contra el sistema económico-político imperante? ¿Quién es el enemigo interno de las Fuerzas Armadas, la policía y los paramilitares?

El actual presidente de Guatemala, Otto Pérez Molina, es un ex militar (Kaibil, y entrenado en la Escuela de las Américas) implicado en los operativos de genocidio (como Operación Sofía) hacia principios de la década de 1980, y miembro de la élite de inteligencia del ejército en los noventa. Una semana después de las elecciones presidenciales, militares retirados y familiares realizaron una marcha por la ciudad de Guatemala pidiendo libertad para los que "lucharon por la libertad". Al mismo tiempo, grupos reaccionarios elaboraron una "lista negra" con los responsables de secuestros y "desapariciones" perpetradas por la guerrilla. ${ }^{94}$ Esto no es menor en un escenario donde se recrudece la concentración y polarización de los recursos, siempre vinculados a la tenencia y los derechos sobre la tierra. Tal como se ha mencionado, aumentaron las tensiones y conflictos sociales en torno a los megaproyectos y las medidas tomadas desde el Estado y por las empresas para acabar con esto, haciendo de la democracia una mera fachada institucional, carente de sustancia.

\section{REFLEXIONES FINALES}

Durante el periodo revolucionario se impulsó la lucha contra el capital extranjero y los monopolios, la reforma agraria, la lucha por los derechos de los trabajadores, la educación y la inclusión social y económica. Ese proyecto de país fue eliminado de raíz, desde adentro, a manos de los altos mandos militares, la oligarquía terrateniente, la Iglesia católica, sectores de clase media y grupos vinculados al capital internacional. Desde fuera, gracias a la intervención estadounidense y la pasividad de los países de América Latina ante el derrocamiento de un gobierno democrático. Esto preparó el terreno para la represión sistemática

93 Annie Bird, "Drugs and Business: Central America Faces Another Round of Violence", en NACLA Report on the Americas, vol. 45, núm. 1, 2012, p. 35.

${ }^{94}$ Kate Doyle, "Justice in Guatemala", en ibid., p. 41. 
por parte del Estado, por medio de la militarización para garantizar la exclusión económica y política de las mayorías en un contexto en el que las fuerzas contrarrevolucionarias no lograron adquirir legitimidad.

La "transición a la democracia" abrió posibilidades para la reconstrucción de la memoria, la recuperación de los caminos y la unidad para la lucha. Los juicios a militares genocidas, la organización de las comunidades para realizar los referéndums y la rearticulación de las estrategias de lucha entre diferentes sectores es un hecho. Los pueblos ya conocen sus derechos. Sin embargo, frente a esta toma de conciencia, el Estado guatemalteco recurre una vez más a las fuerzas de seguridad para lograr la "estabilidad" en lugar de plantear alternativas para la redistribución de los recursos y la riqueza.

En este contexto, la democracia formal vuelve a ser utilizada como fachada de un Estado, el cual confunde las fuerzas de seguridad privada, los militares y paramilitares que operan contra cualquier proyecto tendiente a revertir la polarización y concentración de los recursos y la riqueza. Esto descalifica los Acuerdos de Paz (ique tanto costaron!) y contribuye a redefinir el "enemigo interno" en figuras como la "inseguridad", las "bandas urbanas", el "narcotráfico" o el "crimen organizado" como fachadas del verdadero enemigo, que sigue siendo la lucha de los pueblos por sus derechos. Esto es posible en el marco de programas de seguridad regional (como la Iniciativa Regional de Seguridad para América Central y la Iniciativa Mérida) promovidos por Estados Unidos para luchar contra el crimen organizado.

Ante este escenario, se abre el interrogante de cuál es la posibilidad de la democracia en un ámbito donde no está claro el predominio de lo civil sobre lo militar, donde nuevamente el Estado se opone a las decisiones de las comunidades, desgastando la legitimidad de una democracia que, al estar restringida a aspectos formales mínimos, es peligrosamente presentada como "incapaz" de conducir al desarrollo, la justicia y la paz.

Recibido: 7 de enero, 2012. Aceptado: 19 de septiembre, 2012. 